\title{
Diabetes-Care Quality among Veterans in Southwest Indiana, United States
}

\author{
${ }^{1}$ Government Medical College, Medical Enclave, Amritsar, Punjab, \\ India \\ ${ }^{2}$ Washington University of Health and Science, San Pedro, Belize \\ ${ }^{3}$ Gian Sagar Medical College and Hospital, Ram Nagar, Banur, \\ Punjab, India \\ ${ }^{4}$ Division of Endocrinology, Department of Internal Medicine, \\ St Vincent Medical Group, Evansville, Indiana, United States
}

Harsimran Kaur ${ }^{1} \quad$ Aayushi Sood ${ }^{2}$ Devkarn Sandhu ${ }^{3}$ Vishal Bhatia ${ }^{4}$

\begin{abstract}
Address for correspondence Vishal Bhatia, MBBS, MD, FACE, Division of Endocrinology, Department of Internal Medicine, St Vincent Medical Group, Evansville, Indiana 47630, United States (e-mail: vishal.bhatia@ascension.org).
\end{abstract}

J Soc Health Diab 2019;7:84-86

\begin{abstract}
Keywords

- diabetes mellitus type 2

- mission act 2019

- veterans

Objective Diabetes is more prevalent among U.S. veterans than the general population. The study is among the U.S. veterans in Southwest Indiana with diabetes mellitus type 2 to understand their demographics, comorbidities, and complications that could help guide strategies to address the prevalence of diabetes among U.S. veterans in the area. Earlier diagnosis and referral to the specialty clinics approaches are needed to lower the prevalence of diabetes among U.S. veterans and preventing diabetes-related complications to improve their health status.

Materials and Methods We constructed a retrospective study of veterans in the Southwest area with medically treated diabetes type 2, who received Veterans Health Administration primary care and were referred to our specialty clinic. We categorized based on demographics, comorbidities, initial HbA1c percentage, and complications, and created multivariable models.

Results In our study of 80 U.S. veterans with diabetes, $90 \%$ had comorbidities already when they presented to our clinic. Diabetes was more prevalent in patients older than 60 years. Around $60 \%$ of patients presented with complications such as neuropathy, coronary arterial disease, and heart problems. We calculated the HbA1c when the patients came, and around $42 \%$ had hemoglobin A1c (HbA1c) over $10 \%$. Patients with exposure to Agent Orange during the Vietnam War had HbA1c over $9 \%$.

Conclusion U.S. veterans with diabetes type 2 referred to the specialty clinic have high HbA1c and more complications on their first visit. Therefore, veterans need to be referred early to the specialty clinics during the course to improve their health status. Mission's Act 2019 empowers veterans with increased access to community care.
\end{abstract}

\section{Introduction}

Diabetes is a highly prevalent chronic disease among U.S. adults and is associated with multiple chronic conditions, including cardiovascular diseases, stroke, and disorders leading to amputation. Diabetes is more prevalent among U.S. veterans, who make up $9 \%$ of the civilian U.S. population, than among the general population and affects nearly $25 \%$ of U.S. Department of Veterans Affairs (VA) patients. ${ }^{1,2}$ It is the main cause of microvascular complications (nephropathy, neuropathy, and retinopathy); patients with diabetes also experience higher rates of macrovascular complications (heart disease and stroke) and a twofold increase in mortality compared with other patients. ${ }^{3}$

The objective of our study is to understand veteran population's demographics, comorbidities, and diabetes complications that could guide strategies to address veterans being referred to private clinics sooner. received

August 28, 2019

accepted after revision

September 3, 2019
DOI https://doi.org/

$10.1055 / \mathrm{s}-0039-3400215$

ISSN 2321-0656.
License terms

(ㅇ) (1) $\ominus \circledast$ 


\section{Materials and Methods}

We constructed a retrospective study of veterans with type 2 diabetes in Southwest Indiana region, who were referred to our clinic from the Veterans Hospital.

Diabetes in a participant was defined as having at least 1 of 4 conditions: (1) a glycated hemoglobin A1c (HbA1c) of $6.5 \%$ or higher, (2) fasting plasma glucose of $126 \mathrm{mg} / \mathrm{dL}$ or higher, (3) a 2-hour plasma glucose of $200 \mathrm{mg} / \mathrm{dL}$ or higher, or (4) a diagnosis of diabetes by a physician or other health care provider. $^{4}$

We characterize our study's baseline demographics, comorbidities, insulin use, and diabetes complications. Demographic factors included (1) age (categorized as $<40$ years, 40-49 years, 50-59 years, 60-69 years, $70-79$ years, or $\geq 80$ years), (2) sex (male or female), (3) race (White, Black or African-American,), and medical comorbidities including hypertension and hyperlipidemia. Diabetes complications included coronary artery disease, congestive heart failure, and cerebrovascular disease, as well as diabetic retinopathy, neuropathy, and nephropathy when they first presented in our clinic.

Veterans who served in Vietnam, the Korean demilitarized zone, or another area where Agent Orange was sprayed could have developed diabetes type 2 . We have included exposure to Agent Orange as one the variables in our study to learn about the complications and comorbidities they have when presented to our clinic.

\section{Result}

Eighty subjects with diabetes mellitus type 2 were evaluated. The mean age was 61.4 years and $81.25 \%$ were men. Roughly $90 \%$ had comorbidities, including hypertension and dyslipidemia, when they first presented in our clinic. A higher prevalence of diabetes complications was seen during the initial visit-6.25\% had retinopathy, $67.5 \%$ had neuropathy, and $25 \%$ had nephropathy (-Table $\mathbf{1}$ ).

The mean HbA1C was 10.8. Approximately $60.7 \%$ patients had initial A1C greater than 9\% when came to our clinic. Most of the patients were already on insulin regimen; $14.7 \%$ patients who were exposed to Agent Orange during Vietnam War had more complications, including previous history of myocardial infarction, stroke, or peripheral neuropathy.

\section{Discussion}

Diabetes is more prevalent among U.S. veterans than among the general population. ${ }^{5}$ Diabetes is preventable for many people and treatable, but people with undiagnosed diabetes have delays in receiving effective treatment and, thus, are more likely to develop complications such as coronary artery diseases and retinal microvascular diseases than people with diabetes who receive treatment. ${ }^{6}$
Table 1 Demographic of our study population with diabetes-related complications

\begin{tabular}{|c|c|}
\hline Demographic variables & All patients (80) \\
\hline \multicolumn{2}{|l|}{ Age $(y, \%)$} \\
\hline$<40$ & 5 \\
\hline $40-50$ & 6.25 \\
\hline $50-60$ & 23.75 \\
\hline $60-70$ & 42.5 \\
\hline $70-80$ & 22.5 \\
\hline \multicolumn{2}{|l|}{ Gender (\%) } \\
\hline Male & 81.25 \\
\hline Females & 18.75 \\
\hline \multicolumn{2}{|l|}{ Race (\%) } \\
\hline Caucasian & 88.75 \\
\hline African American & 11.25 \\
\hline \multicolumn{2}{|l|}{ Comorbidities \% } \\
\hline Hypertension & 92.5 \\
\hline Dyslipidemia & 96.25 \\
\hline \multicolumn{2}{|l|}{$\mathrm{BMI}\left(\mathrm{Kg} / \mathrm{m}^{2}, \%\right)$} \\
\hline $18.5-24.9$ & 6.25 \\
\hline $25-29.9$ & 17.5 \\
\hline$>30$ & 76.25 \\
\hline \multicolumn{2}{|l|}{ Complications (\%) } \\
\hline Neuropathy & 67.5 \\
\hline Nephropathy & 25 \\
\hline Retinopathy & 6.25 \\
\hline Heart conditions & 18.75 \\
\hline Peripheral Vascular Disease & 11.25 \\
\hline \multicolumn{2}{|l|}{ Tobacco abuse } \\
\hline Nonsmoker & 47.5 \\
\hline Current & 22.5 \\
\hline Former & 30 \\
\hline Insulin use (\%) & 88.75 \\
\hline Exposure to Agent Orange (\%) & 14.75 \\
\hline \multicolumn{2}{|l|}{ Initial HbA1C (\%) } \\
\hline$<7$ & 8.80 \\
\hline $7.1-8$ & 15 \\
\hline $8.1-9$ & 15 \\
\hline $9.1-10$ & 19 \\
\hline $10.1-11$ & 16.4 \\
\hline $11.1-12$ & 7.6 \\
\hline $12.1-13$ & 6.3 \\
\hline $13.1-14$ & 3.8 \\
\hline$>14$ & 7.6 \\
\hline
\end{tabular}


The U.S. military used Agent Orange to clear plants and trees during the Vietnam War and the veterans who were exposed to it are eligible for disability compensation through the Department of Veterans Affair. The studies have found that diabetes is associated with Agent Orange exposure in Vietnam, ${ }^{7.8}$ as well as in Korean Vietnam veterans exposed to agent orange. ${ }^{9}$

Mission's Act 2019 allows veterans to get care from private-sector providers if they meet certain criteria:

1. They need a service that is not available at VA medical facility.

2. They live in a territory that does not have a full-service VA medical facility.

3. The wait time to see primary care at VA medical facility exceeds 20 days or their drive time to a VA facility exceeds 29 minutes.

The goal of the new policy is to provide veterans with easier, streamlined access to health care. It will strengthen the nationwide VA health care system by empowering veterans with more health care options. Through Mission Act 2019, veterans who have been diagnosed by diabetes mellitus type 2 by their health care providers can see private specialists early rather than late to prevent getting complications from diabetes. This empowers veterans with increased access to community care.

Efforts are to be made to provide comprehensive approach to care, expand community care network, or network of non-VA providers delivering care under the VA umbrella, which will expand patient access to care beyond the means VA currently has.

\section{Conflict of Interest}

None declared.

\section{References}

1 US Census Bureau. Veterans Day. Available at: https://www. census.gov/topics/population/veterans/about/veterans-day. html. Accessed October 30, 2017

2 US Department of Veterans Affairs. Veterans Health Administration: close to 25 percent of VA patients have diabetes. Available at: https://www.va.gov/health/NewsFeatures/20111115a. asp. Updated April 17, 2015. Accessed February 23, 2017

3 Miller DR, Safford MM, Pogach LM. Who has diabetes? Best estimates of diabetes prevalence in the Department of Veterans Affairs based on computerized patient data. Diabetes Care 2004;27(Suppl 2):B10-B21

4 National Diabetes Statistics Report, 2017: estimate of diabetes and its burden in the United States. Available at: https:// www.cdc.gov/diabetes/pdfs/data/statistics/national-diabetesstatistics-report.pdf. Accessed October 30, 2017

5 Veterans Health Administration. Close to 25 percent of VA patients have diabetes. Available at: https://www.va.gov/ health/NewsFeatures/20111115a.asp. Updated April 17, 2015. Accessed February 23, 2017

6 Erin Bagalman. US Congressional Research Service. The number of veterans that use VA health care services: a fact sheet. June 2014. R43579. Available at: https://fas.org/sgp/crs/misc/ R43579.pdf. Accessed March 10, 2017

7 Michalek JE, Pavuk M. Diabetes and cancer in veterans of Operation Ranch Hand after adjustment for calendar period, days of spraying, and time spent in Southeast Asia. J Occup Environ Med 2008;50(3):330-340

8 Kang HK, Dalager NA, Needham LL, et al. Health status of Army Chemical Corps Vietnam veterans who sprayed defoliant in Vietnam. Am J Ind Med 2006;49(11):875-884

9 Yi SW, Hong JS, Ohrr H, Yi JJ, Yi SW. Agent Orange exposure and disease prevalence in Korean Vietnam veterans: the Korean veterans health study. Environ Res 2014;133:56-65 